\title{
COOPERAÇÃo JURídica INTERNACIONAL: ATRIBUIÇÕES LEGAIS NO AUXÍlIO DIRETO
}

\author{
MiLTON FORNAZARi JÚNIOR
}

Departamento de Polícia Federal

$$
\text { ○浆亏 }
$$

\section{RESUMO}

Trata-se de estudo acerca da cooperação jurídica internacional aplicada na persecução penal, por meio do auxílio direto (mutual legal assistance), analisada em especial as atribuições constitucionais e legais para o seu manuseio.

Palavras-Chave: Persecução Penal. Cooperação Jurídica Internacional. Auxílio Direto, Atribuições. Competência..

\section{INTRODUÇÃ̃o}

A cooperação jurídica internacional entre o Brasil e os diversos países da comunidade internacional se verifica por meio dos institutos tradicionais: extradição, carta rogatória e homologação de sentença estrangeira. Atualmente, dois outros institutos surgiram em tratados internacionais recentes: o procedimento da transferência de presos ou condenados e o denominado auxílio direto ou mutual legal assistance (“MLA”)1, em matéria civil e penal.

No âmbito do presente estudo, buscou-se delimitar brevemente o fundamento constitucional e legal do auxílio direto em matéria penal, atualmente previsto no artigo $216-0, \S 2^{\circ}$, do Regimento Interno do Superior Tribunal de Justiça ${ }^{2}$, bem como identificar a atribuição le-

1 Cabe, desde já, uma primeira observação. Algumas autoridades brasileiras se referem à peça de auxílio direto como "MLAT", o que, na verdade, se trata da sigla correspondente à expressão inglesa mutual legal assistance treaty. Referida expressão se refere aos tratados nos quais o regime jurídico do mutual legal assistance é previsto, uma vez que treaty significa tratado ou acordo em português. Portanto, o correto é referir-se à peça como Auxílio Direto, ou ainda, Assistência Jurídica ou Auxílio Jurídico, cuja tradução corresponde a mutual legal assistance (MLA).

2 “Artigo 216-O. $\$ 2^{\circ}$ Os pedidos de cooperação jurídica internacional que tiverem por objeto atos 
gal das autoridades brasileiras para a expedição do auxílio direto ativo (ao exterior), bem como para o cumprimento do auxílio direto passivo (oriundo do exterior).

\section{O Surgimento do Auxílio Direto em Matéria Penal}

O chamado fenômeno da globalização, verificado a partir da segunda metade do século XX, aproximou as nações e as pessoas das mais diversas nações, o que foi potencializado com o advento da internet, trazendo uma nova realidade, com diversos efeitos, tanto positivos como negativos.

Os efeitos negativos se revelaram pelo aumento dos litígios internacionais e pela facilitação da prática dos crimes transnacionais, compreendidos como aqueles cuja preparação, execução ou resultado são repartidos em fases diversas, ocorrendo parte delas em um país e parte em outro ou em mais países.

O crime transnacional, de acordo com a Convenção de Palermo ${ }^{3}$, se configura em qualquer das seguintes hipóteses: a) quando cometido em mais de um Estado; b) quando cometido em um Estado, mas sua preparação foi substancialmente feita em outro; c) quando cometido em um Estado, mas a organização criminal do grupo é estabelecida em outro Estado; e d) quando cometido em um Estado, mas tem efeitos substanciais em outro.

Para se ter uma ideia da nocividade do crime transnacional, levantamento realizado pelo Fundo Monetário Internacional identificou que a lavagem de dinheiro transnacional faz circular cerca de $2 \%$ a $5 \%$ do produto interno bruto mundial, anualmente, por meio de operações bancárias e financeiras internacionais, além do uso de empresas offshore sediadas em paraísos fiscais (PEREIRA NETO, 2005, p. 155).

Nesse contexto mundial, surgiu a necessidade de uma maior e eficaz cooperação internacional entre todos os países, a fim de adequar melhor o combate à criminalidade transnacional na nova realidade global.

\footnotetext{
que não ensejem juízo deliberatório do Superior Tribunal de Justiça, ainda que denominados de carta rogatória, serão encaminhados ou devolvidos ao Ministério da Justiça para as providências necessárias ao cumprimento por auxílio direto."

3 Incorporada no nosso ordenamento jurídico com o status de lei ordinária, pelo Decreto n ${ }^{\circ}$.015/2004.
} 
$\mathrm{Na}$ Constituição Federal, a mais ampla cooperação com os outros países é destacada como princípio, conforme preceitua o artigo $4^{\circ}$, inciso IX:

Art. $4^{\circ}$ A República Federativa do Brasil rege-se nas suas relaçôes internacionais pelos seguintes princípios: (...)

$I X$ - cooperação entre os povos para o progresso da humanidade; (...).

Os instrumentos tradicionais de cooperação jurídica internacional, como as cartas rogatórias e a homologação de sentença estrangeira já não se mostram mais eficazes para a produção de provas, ou para a efetivação de medidas de indisponibilidade de bens e repatriação de valores pelo mundo afora, ao menos com a eficiência que se exige atualmente no combate a essa espécie de criminalidade.

Tornou-se necessário facilitar e simplificar a cooperação jurídica entre os países, tornando-a a mais ampla possível, em especial com a rápida comunicação e ciência das autoridades competentes para a adoção das medidas mais adequadas ao sucesso de uma investigação ou de um processo penal.

Por outro lado, era importante a criação de um sistema de normas, um regime jurídico, que respeitasse e assegurasse os direitos fundamentais do indivíduo frente à ação estatal.

Seguindo esse entendimento, os países passaram a repensar o modelo de cooperação internacional, desde a segunda metade do Século XX, com a celebração de tratados bilaterais, regionais e multilaterais.

Um dos pioneiros tratados bilaterais que previu os contornos do regime jurídico do atual auxílio direto penal ("mutual legal assistance") foi o assinado entre os EUA e a Suíça, com vigência iniciada no ano de 1977.

A partir da década de 1990, com a assinatura dos dois primeiros tratados bilaterais pelo Brasil (com Itália e França) ${ }^{4}$, a cooperação internacional passou a ser repensada internamente, sob o prisma de torná-la mais efetiva.

A partir da assinatura com os Estados Unidos da América do acordo bilateral sobre cooperação jurídica em matéria penal, em 2001, o auxílio direto no Brasil teve seus contornos bem definidos e sua aplicação efetivada,

4 Incorporados ao nosso ordenamento, respectivamente, pelos Decretos nº 863/1993 e n 3.324/1999. 
devido ao grande volume de relações entre os dois países, bem como em virtude da maior precisão técnica do tratado.

O MLAT, abreviatura para Mutual Legal Agreement Treaty, foi incorporado ao nosso ordenamento por meio do Decreto $\mathrm{n}^{\circ} 3.810 / 2001 \mathrm{com}$ a denominação de Acordo de Assistência Judiciária em Matéria Penal.

Desde então, diversos outros tratados bilaterais foram celebrados pelo Brasil, tendo basicamente como modelo o padrão adotado no chamado "MLAT".

Foram assinados e promulgados no nosso ordenamento vinte tratados bilaterais, até o momento, que estão em plena vigência, com os seguintes países: Canadá (Decreto no 6.747/2009); China (Decreto no 6.282/2007); Colômbia (Decreto n ${ }^{\circ} 3.895 / 2001$ ); Coréia do Sul (Decreto n ${ }^{\circ} 5.721 / 2006$ ); Cuba (Decreto $n^{\circ}$ 6.462/2008); Espanha (Decretos no 6.681/2008 e ${ }^{\circ}$ 8.048/2013); Estados Unidos da América (Decreto no 3.810/2001); França (Decreto $\left.n^{\circ} 3.324 / 1999\right)$; Honduras (Decreto $\left.n^{\circ} 8.046 / 2013\right)$; Itália (Decreto $n^{\circ}$ 862/1993); México (Decreto $\left.n^{\circ} 7.595 / 2011\right)$; Nigéria (Decreto $n^{\circ} 7.582 / 2011$ ); Panamá (Decreto $n^{\circ} 7.596 / 2011$ ); Paraguai (Decreto $n^{\circ}$ 139/1995); Peru (Decreto $n^{\circ} 3.988 / 2001$ ); Portugal (Decreto $n^{\circ}$ 1.320/1994); Reino Unido (Decreto $\mathrm{n}^{\circ}$ 8.047/2013); Suíça (Decreto $\mathrm{n}^{\circ}$ 6.974/2009); Suriname (Decreto $n^{\circ}$ 6.832/2009); e Ucrânia (Decreto ${ }^{\circ}$ $5.984 / 2006)$.

Paralelamente, em virtude da especificidade do combate a cada espécie de crime transnacional, ou em razão do processo de integração regional do Mercosul, vários outros tratados internacionais multilaterais também foram assinados pelo Brasil.

Entre os mais importantes para o nosso estudo, devido à previsão do instituto do auxílio direto, estão os seguintes: "Convenção de Viena", ou Convenção contra o Tráfico Ilícito de Entorpecentes e Substâncias Psicotrópicas (Decreto no 154/1991); Protocolo de Assistência Jurídica Mútua em Assuntos Penais no Mercosul (Decreto no 3.468/2000); "Convenção de Palermo", ou Convenção das Nações Unidas contra o Crime Organizado Transnacional (Decreto n 5.015/2004); "Convenção de Mérida”, ou Con-

5 A Convenção de Palermo contra o crime organizado, ainda foi aditada por outros protocolos internacionais, referentes aos crimes de tráfico de pessoas (Decretos no 5.016/2004 e n 5.017/2004) e tráfico de armas (Decreto n ${ }^{\circ}$ 5.941/2006). 
venção das Nações Unidas contra a Corrupção (Decreto n 5.687/2006); e Convenção Interamericana sobre Assistência Mútua em Matéria Penal (Decreto $\left.\mathrm{n}^{\circ} 6.340 / 2008\right)$.

Como podemos verificar, a grande maioria dos tratados internacionais sobre o auxílio direto foram criados após o ano 2000, o que demonstra a novidade do instituto no ordenamento jurídico brasileiro.

O referido instituto possui contornos jurídicos muito mais ágeis do que os da carta rogatória e os da homologação de sentença estrangeira, em especial a desconcentração da competência jurisdicional e a possibilidade de atos executórios no território do Estado requerido, sem olvidar da sua conformidade com a legislação interna brasileira e com a Constituição Federal.

Nesse sentido, precisa a lição de Teori Zavascki:

as relaçôes internacionais, no âmbito do que se denomina, genericamente, de cooperação jurídica, estão previstas, fundamentalmente, em normas de direito público internacional, estabelecidas em acordos bilaterais, regionais e multilaterais, que têm proliferado fecundamente em todo o mundo nas últimas décadas. (...) O conjunto dessas normas internacionais sobre cooperação jurídica evidencia claramente a preocupação das Nações e dos organismos internacionais em estabelecer novos paradigmas de assistência mútua nessa área, a fim de enfrentar, com agilidade e eficiência, os graves problemas de aplicação das leis penais, numa realidade mundial globalizada. (ZAVASCKI, 2010, P. 17-18)

\section{O Auxílio Direto em Matéria Penal}

O auxílio direto em matéria penal, de acordo com seu regime jurídico no Brasil, constitui um instituto de direito público internacional e de direito processual penal, previsto em tratado internacional, devidamente incorporado ao ordenamento jurídico interno, com status de lei ordinária, por meio do qual se estabelece o intercâmbio entre países acerca de documentos, provas, atos e medidas processuais constritivas patrimoniais, por intermédio de uma Autoridade Central $^{6}$, incumbida da promoção da pretensão de um

6 A AUTORIDADE CENTRAL é figura típica do regime jurídico do mutual legal assistance. Tratase de um órgão em cada país por meio do qual deve tramitar celeremente o auxílio direto, além de dispensar a necessidade da legalização consular para as informações e provas obtidas por meio do auxílio direto, tornando assim menos burocrática a cooperação jurídica internacional em matéria 
País, no interesse de uma investigação criminal ou de um processo penal no exterior (ativo) ou no Brasil (passivo).

O auxílio direto penal é um instituto híbrido, pois é afeto tanto ao Direito Público Internacional, como ao Direito Processual Penal.

O seu conteúdo, compreendido pelas medidas que constituem o seu objeto, trata da realização de atos de investigação criminal e processuais penais em outro país, desde que diversos da extradição, configurando uma medida incidental, acessória e cautelar a um feito principal de natureza processual penal: a persecução penal em trâmite no País requerente, materializada em uma investigação criminal (fase pré-processual) ou em uma ação penal (fase processual).

Com efeito, ao tratar da cooperação jurídica, por meio do auxílio direto, a Convenção de Palermo determina que os países signatários prestarão reciprocamente, toda assistência possível nas investigações, nos processos e em outros atos judiciais relativos às organizações criminosas ${ }^{7}$.

O Acordo Brasil/EUA também segue o mesmo regime, determinando que ambos os países: "se obrigam a prestar a assistência mútua, em matéria de investigação, inquérito, ação penal, prevenção de crimes e processos relacionados a delitos de natureza criminal"8.

Outro tratado também muito utilizado, firmado entre o Brasil e a Suíça, dispõe que os Estados deverão conceder um ao outro a "mais ampla cooperação jurídica em qualquer investigação ou procedimento judiciário

penal. No Brasil vigora o modelo executivo, assim como na Espanha, Inglaterra, Suécia, Suíça e Uruguai, dentre outros. Desta maneira, a autoridade central integra o Poder Executivo, trata-se do Departamento de Recuperação de Ativos e Cooperação Jurídica Internacional (DRCI), na Secretaria Nacional de Justiça, do Ministério da Justiça, criado administrativamente para essa finalidade. Apenas em dois tratados internacionais, excepcionalmente (com Portugal e com o Canadá), a autoridade central brasileira é o Ministério Público Federal.

7 Artigo 18, item 1, da Convenção das Nações Unidas contra o Crime Organizado Transnacional (Decreto $\mathrm{n}^{\circ}$ 5.015/2004).

8 Artigo $1^{\circ}$, item 1, do Acordo de Assistência Judiciária em Matéria Penal entre o Governo da República Federativa do Brasil e o Governo dos Estados Unidos da América (Decreto no 3.810/2001). 
relativos a delitos cuja repressão é da jurisdição do Estado requerente"'.

Por esses dispositivos, com redação muito similar em todos os tratados sobre o tema, se verifica que a medida de auxílio direto deve estar associada sempre a uma persecução penal, devidamente materializada.

De fato, como corolário do devido processo legal, não se admitem processos ou investigações criminais cujos atos não estejam materializados em procedimento formais. No Brasil, a fase pré-processual é materializada pelo inquérito policial, relativa à investigação criminal, e a fase processual pela ação penal.

Portanto, qualquer expedição de auxílio direto, no Brasil, deverá ter sido determinada incidentalmente, no curso de um dos dois procedimentos criminais acima mencionados.

Por outro lado, o auxílio direto passivo, ou seja, aquele que será cumprido no Brasil, por interesse de outro país, visando a realização dos atos acima referidos, também deverá estar vinculado no exterior a um procedimento formal e materializado, referente a uma investigação criminal ou a um processo penal, ainda que de natureza e disciplina diferente da persecução penal brasileira.

\section{A Atribuição para Expedição do Auxíllo Direto Ativo}

Como já se viu acima, o auxílio direto deve ser expedido durante a fase da investigação criminal ou da ação penal, cabendo ao titular de cada uma delas a sua iniciativa.

No Brasil, de regra, cabe ao Delegado de Polícia a titularidade na fase do inquérito policial, e ao membro do Ministério Público na fase da ação penal.

Em que pese o Ministério Público não seja o titular do inquérito policial no Brasil, agindo com custus legis na fase pré-processual, em algumas investigações tem se verificado sua participação atípica, mediante a expedi-

9 Artigo $1^{\circ}$, item 1, Acordo de Assistência Judiciária em Matéria Penal entre o Governo da República Federativa do Brasil e a Confederação Suíça (Decreto no 6.974/2009). 
ção própria de auxílios diretos ao exterior.

Além do entendimento atual de membros do Ministério Público, acerca da possibilidade da condução da investigação criminal e da ação penal com exclusividade pelo Ministério Público, alguns tratados mais antigos, e em especial da década de 1990 e, portanto, ainda com menor precisão jurídica, contribuíram com essa situação.

Também se deve destacar que a expedição de auxílio direto não se traduz como medida típica por parte do juiz que supervisiona o inquérito policial ou do que julga a ação penal. Não obstante, nada impede que o juiz, no exercício da supervisão e do controle do inquérito policial, bem como na qualidade de julgador na ação penal, também expeça a solicitação ao País requerido.

A diferença é que no auxílio direto, o juiz submeterá sua decisão à apreciação de mérito pelo Poder Judiciário de outro país, na qualidade de requerimento, diferentemente do que ocorre com a carta rogatória.

Na carta rogatória, o País requerido se limita a reconhecer a validade e eficácia de uma decisão judicial do País requerente, desde que atendidos os requisitos formais, sem discussão acerca do mérito.

No auxílio direto, ao contrário, submete-se ao Poder Judiciário no País requerido a análise do mérito da solicitação formulada, aplicando-se a lei do país requerido (locus regit actum), em regra, para que a medida seja deferida ou não.

Nesse sentido, precisa é a lição de Gilson Dipp:

pelo pedido de auxílio jurídico direto, o Estado estrangeiro não se apresenta na condição de juiz, mas de administrador. Não encaminha uma decisão judicial a ser aqui executada, mas solicita assistência para que, no território nacional, sejam tomadas as providências necessárias à satisfação do pedido. Se as providências solicitadas no pedido de auxilio estrangeiro exigirem, conforme a lei brasileira, decisão judicial, deve a autoridade competente promover, na Justiça brasileira, as ações judiciais necessárias. $O$ Estado estrangeiro, ao se submeter à alternativa do pedido de auxílio jurídico direto, concorda que a autoridade judiciária brasileira, quando a providência requerida exigir pronunciamento jurisdicional, analise o mérito das razóes do pedido. O mesmo não ocorre no julgamento da carta 
rogatória pelo Superior Tribunal de Justiça, cujo sistema exequatur impede a revisão do mérito das razões da autoridade estrangeira, salvo para verificar violação à ordem pública e à soberania nacional. Na carta rogatória, dá-se eficácia a uma decisão judicial estrangeira, ainda que de natureza processual ou de mero expediente. No pedido de auxilio, busca-se produzir uma decisão judicial doméstica e, como tal, não-sujeita ao juizo de delibação . (DIPP, 2007, p. 40)

Destacada essa característica do auxílio direto, retornamos ao escopo do presente estudo, por meio do qual se verifica que o auxílio direto em matéria penal é instituto de manuseio típico pelo presidente da investigação criminal e pelo titular da ação penal, ou seja, o Delegado de Polícia e o membro do Ministério Público, respectivamente.

De fato, a maioria dos tratados, conforme exemplificam os dispositivos transcritos acima, estabelece a mais ampla cooperação jurídica no âmbito das investigações criminais.

$\mathrm{O}$ artigo $6^{\circ}$, do Código de Processo Penal impõe a obrigação ao Delegado de Polícia, na qualidade de autoridade policial, de investigar os fatos ilícitos de natureza penal, o que é feito pela formalização do inquérito policial ${ }^{10}$.

$\mathrm{O}$ artigo $2^{\circ}$ e seus parágrafos, da Lei $\mathrm{n}^{\circ} 12.830 / 2013$, também estabelece a titularidade da investigação criminal pelo Delegado de Polícia ${ }^{11}$.

Já o Ministério Público possui a titularidade da promoção da ação penal, conforme previsto no artigo 129 , inciso I, da Constituição Federal ${ }^{12}$, o que determina a sua atribuição para a expedição de auxílio direto no âmbito da instrução da ação penal, em conformidade com a redação dos dispositivos em tratados acima descritos, a título exemplificativo.

10 "Art. 6o Logo que tiver conhecimento da prática da infração penal, a autoridade policial deverá: (...); III - colher todas as provas que servirem para o esclarecimento do fato e suas circunstâncias;"

11 Art. 2o As funções de polícia judiciária e a apuração de infrações penais exercidas pelo delegado de polícia são de natureza jurídica, essenciais e exclusivas de Estado. $₫$ 1o Ao delegado de polícia, na qualidade de autoridade policial, cabe a condução da investigação criminal por meio de inquérito policial ou outro procedimento previsto em lei, que tem como objetivo a apuração das circunstâncias, da materialidade e da autoria das infrações penais. $₫ 20$ Durante a investigação criminal, cabe ao delegado de polícia a requisição de perícia, informações, documentos e dados que interessem à apuração dos fatos.

12 "Art. 129. São funções institucionais do Ministério Público: I - promover, privativamente, a ação penal pública, na forma da lei;" 


\section{Da Atuação do Delegado de Polícia no Auxílio Direto Ativo}

Desta maneira, durante a instrução do inquérito policial, caso o Delegado de Polícia Federal ou o Delegado de Polícia Civil (a depender do crime investigado ser de competência federal ou estadual) verifique a hipótese legal da obtenção formal de informações e provas no exterior, nas mesmas hipóteses em que detém atribuições legais para agir de ofício ou representar em juízo no Brasil, demandará diretamente ao Estado requerido, por meio do auxílio direto, que será enviado pela Autoridade Central brasileira à sua congênere no País requerido, instruindo a medida para apreciação do mérito pelas autoridades competentes no exterior.

Ou seja, a autoridade brasileira submeterá ao Estado requerido o legítimo interesse de ser realizada a prática de determinado ato no exterior, com a finalidade de instruir um procedimento criminal no Brasil.

A título de exemplo, imagine que um Delegado de Polícia Federal, em sede de inquérito policial, encontre indícios suficientes de materialidade e autoria da prática de determinado crime no Brasil e, além disso, provas de que o investigado mantém valores depositados em conta bancária, em outro país, obtidos com a prática do crime.

Nessa hipótese, a autoridade brasileira, no caso o Delegado de Polícia, formula a medida de auxílio direto, instruindo-a com as provas dos crimes praticados e submete a pretensão da quebra do sigilo bancário e do sequestro dos valores ilícitos ao País requerido, por meio das autoridades centrais dos dois países.

No exemplo citado, por se tratar de medida sujeita à apreciação judicial no Brasil, para ter validade no direito interno, pode se discutir se deverá obter ou não a autorização do afastamento do sigilo bancário e a decretação do sequestro de valores do investigado no exterior, também junto ao juiz competente no Brasil.

Prosseguindo nesse exemplo, se o Estado requerido tiver uma legislação semelhante à brasileira, na qual a constrição de bens também está sujeita à reserva de jurisdição (como ocorre na maioria dos países do mundo ocidental), aí então, por meio de uma Autoridade Central, a demanda brasileira será 
direcionada ao órgão interno com atribuição para propor a medida judicial cautelar cabível, perante o próprio Poder Judiciário do Estado requerido.

Caberá ao juiz do Estado requerido efetuar o juízo de mérito acerca daquele pedido, ou seja, a análise será feita não só quanto à observância ou não dos requisitos formais previstos em tratado, mas também se há realmente indícios suficientes que justifiquem a medida cautelar de constrição patrimonial (juízo de mérito).

Referida medida, se acolhida no Estado requerido, terá o condão de assegurar o ressarcimento da vítima ou do Estado requerente, além de possibilitar o acesso aos documentos de abertura e movimentação da conta no exterior, ou seja, a prova da materialidade do crime transnacional, na hipótese citada.

\section{Atribuiçóes para Cumprimento do Auxílio Direto Passivo}

O mesmo raciocínio no auxílio direto ativo vale para a hipótese de auxílio direto a ser cumprido no Brasil: se a autoridade estrangeira encaminhar ao Brasil, por meio de auxílio direto, uma demanda sujeita à reserva de jurisdição, como a quebra dos sigilos bancário e fiscal, o sequestro de bens e valores, a interceptação telefônica etc., a Autoridade Central brasileira deverá encaminhar o pedido ao órgão com atribuições constitucionais para representar em juízo por aquela demanda.

Se a demanda tiver que ser proposta para instruir um processo penal no exterior, o pedido deverá ser encaminhado ao Ministério Público Federal, a quem incumbe promover e acompanhar a ação penal no Brasil, a teor do artigo 129, inciso I, da Constituição Federal.

Na hipótese de se tratar de uma medida cautelar para a instrução de uma investigação criminal no exterior, a medida deverá ser encaminhada à Polícia Federal, o qual detém as atribuições de polícia judiciária da União, nos termos do artigo 144, da Constituição Federal, cabendo aos delegados de Polícia Federal a incumbência de representar em juízo pelas medidas solicitadas. 
Com efeito, a regulamentação do trâmite do auxílio direto pela $\mathrm{Au}$ toridade Central no Brasil, foi feito primeiramente pela Portaria Conjunta MJ/PGR/AGU no 01/2005, por meio da qual a medida seria encaminhada à Advocacia Geral da União, nas questões cíveis, e ao Ministério Público Federal, nas demandas de natureza processual penal.

$\mathrm{Na}$ referida portaria se olvidou, indevidamente, das atribuições constitucionais do delegado de Polícia Federal, previstas no artigo 144, da Constituição Federal, relativas às funções de polícia judiciária da União, bem como do poder de representação, previsto no Código de Processo Penal e nas leis penais e processuais penais, exercido por meio das medidas de natureza cautelar em juízo.

A fim de corrigir, o vício formal, que implicava em ilegalidade e inconstitucionalidade, foi corretamente editada a Portaria no 1876 , do Ministério da Justiça, determinando o encaminhamento do auxílio direto à Polícia Federal, nas hipóteses que não se inserissem no âmbito de atribuições exclusivas do Ministério Público, ou seja, na fase do inquérito policial ${ }^{13}$.

Desta maneira, atualmente, os pedidos de auxílio direto, que versam sobre medidas a serem obtidas na fase da investigação criminal no exterior, deverão ser encaminhados pela Autoridade Central brasileira diretamente à Polícia Federal.

A demanda oriunda do exterior, na hipótese de estar sujeita à necessidade de decisão judicial, conforme dispõe o Direito brasileiro, deverá ser distribuída ao juiz federal competente no local onde deva se realizar o ato pretendido pelo Estado requerente, por representação do delegado de Polícia Federal ou do membro do Ministério Público Federal, a depender do momento processual (inquérito policial ou ação penal).

Trata-se, no caso, de competência jurisdicional constitucional, prevista no artigo 109, incisos II e III, da Constituição Federal ${ }^{14}$, uma vez que a

13 "Art. $1^{\circ}$, Portaria n 1.876-MJ: Os pedidos de cooperação jurídica internacional passiva em matéria penal, que se sujeitam à competência da Justiça Federal, não ensejam juízo de deliberação do Superior Tribunal de Justiça e não se inserem no âmbito de atribuições exclusivas do Ministério Público Federal, nos termos da Portaria Conjunta MJ n 1, de 27 de outubro de 2005, poderão ser encaminhados pelo DRCI ao DPF para que este proceda à distribuição dos pedidos às unidades do Departamento de Polícia Federal com atribuição para promover os atos necessários à cooperação.”

14 “Art. 109. Aos juízes federais compete processar e julgar: (...) II - as causas entre Estado estrangeiro ou organismo internacional e Município ou pessoa domiciliada ou residente no País; III - as causas 
causa terá como fundamento tratado internacional firmado pelo Brasil, bem como envolverá a demanda de Estado estrangeiro.

O auxílio direto também poderá ter como objeto a produção de ato que não dependa da intervenção do Poder Judiciário no Estado requerido, no interesse de uma investigação criminal ou de um processo penal.

Exemplo disso é a expedição de auxílio direto para a oitiva de uma testemunha no País requerido, durante a fase pré-processual, que poderá ser solicitada e cumprida pelas autoridades administrativas com atribuição para a realização da investigação criminal, respectivamente no Estado requerente e no País requerido.

No Brasil, por exemplo, a oitiva deverá ser realizada pelo delegado de Polícia Federal, uma vez que a ele incumbe a presidência da fase pré-processual no Brasil.

Outro exemplo é a requisição de documentos a entes administrativos, cujos conteúdos não estejam sujeitos à reserva de jurisdição (p. ex.: certidão de antecedentes penais, dados de qualificação etc.), que poderá ser encaminhada diretamente pela Autoridade Central, em nosso entendimento, para cumprimento pelo órgão administrativo com atribuições legais.

Melhor seria, de lege ferenda, a edição de uma Lei Geral de Cooperação Jurídica Internacional para tratar dos assuntos regulados nas referidas portarias administrativas, a fim de conferir maior segurança jurídica, tanto na aplicação da lei, como na negociação dos futuros tratados a serem assinados pelo Brasil na área.

Milton Fornazari JúNIOR

Delegado de Polícia Federal, Professor da Academia de Polícia Nacional, Mestre em Direito Penal e Doutorando em Direito Processual Penal pela PUC/SP

E-MAIL:MILTON.MFJ@DPF.GOV.BR 


\title{
INTERNATIONAL Legal CoOperation: Legal DUTIES ON DIRECT AID
}

\author{
ABSTRACT \\ It is the study of international legal cooperation applied in the criminal prosecution, through \\ direct aid (Mutual Legal Assistance), examined in particular the constitutional and legal \\ responsibilities for their handling. \\ KeYwords: Criminal Prosecution. International Legal Cooperation. Direct Aid, \\ Assignments. Competence.

\section{COOPERACIÓN JURÍdica INTERNACIONAL: OBLIGACIONES LEGALES EM MATERIA DE AYUDAS DIRECTAS}

\section{RESUMEN}

Es el estudio de la cooperación jurídica internacional en la persecución penal aplicada, a través de la ayuda directa (asistencia judicial recíproca), examinó en particular, las responsabilidades constitucionales y legales para su manejo.

Palabras Clave: Persecución Penal. Cooperación Jurídica Internacional. Ayudas directas, Competencia .

\section{REFERÊNCIAS}

ABADE, Denise Neves. Direitos fundamentais na cooperação jurídica internacional: extradição, assistência jurídica, execução de sentença estrangeira e transferência de presos. São Paulo: Saraiva, 2013.

ACCIOLY, Hildebrando; NASCIMENTO E SILVA, Geraldo E. e CASELLA, Paulo Borba. Manual de direito internacional público. 16a ed. São Paulo: Saraiva, 2008. 
AMBOS, Kai. Cooperação judiciária penal na Europa. Tradutor: José Paulo Baltazar Junior. In: BALTAZAR JUNIOR, José Paulo; LIMA Luciano Flores de. Cooperação jurídica internacional em matéria penal. Porto Alegre: Verbo Jurídico, 2010, pp. 477-510.

. Prosecuting international crimes at the national and international level: between justice and real politique. In: KALECK, W; RATNER, M.; SINGELSTEIN, T. And Weiss p. (EDS.). International prosecution of human rights crimes - part II. Berlin, Heidelberg: Springer Verlag, 2007, p. 55-68.

ANSELMO, Marcio Adriano. Lavagem de dinheiro e cooperação jurídica internacional. São Paulo: Saraiva, 2013.

ARAS, Vladimir; LIMA Luciano Flores de. Cooperação penal direta pela Polícia ou Ministério Público. In: BALTAZAR JUNIOR, José Paulo; LIMA Luciano Flores de. Cooperação jurídica internacional em matéria penal. Porto Alegre: Verbo Jurídico, 2010, pp. 123-160.

ARAÚJO, Nádia de. A importância da cooperação jurídica internacional para a atuação do Estado brasileiro no plano interno e internacional. In: Manual de cooperação jurídica internacional e recuperação de ativos: cooperação em matéria penal. $2^{\mathrm{a}} \mathrm{ed}$. Brasília: Ministério da Justiça, 2012, pp. 33-50.

. Cooperação Jurídica Internacional no Superior Tribunal de Justiça: Comentários à Resolução no 9/2005. Rio de Janeiro: Renovar, 2010.

. Direito internacional privado: teoria e prática brasileira. $5^{\mathrm{a}} \mathrm{ed}$. Rio de Janeiro: Renovar, 2011.

BALTAZAR JUNIOR, José Paulo; LIMA Luciano Flores de. Cooperação jurídica internacional em matéria penal. Porto Alegre: Verbo Jurídico, 2010.

CASTILHO, Ela Wiecko Volkmer de. Cooperação internacional da execução da pena: a transferência de presos. Revista Brasileira de Ci6encias Criminais. São Paulo, nº 71, 2008, pp. 233-249.

CATELANI, Giulio. I Rapporti internazionali in materia penale:

Estradizione, rogatorie, effetti delle sentenze penali straniere. Milano: Giuffrè, 1995. 
CERVINI, Raúl; TAVARES, Juarez. Princípios de cooperação jurídica penal internacional no Protocolo do Mercosul. São Paulo: Revista dos Tribunais, 2000.

CIAMPI, Annalisa. L'Assunzione di prove all'estero in materia penale. Padova: Cedam, 2003.

COSTA, José de Faria; SILVA, Marco Antônio Marques da (coordenação). Direito Penal Especial, Processo Penal e Direitos Fundamentais: Visão Luso-Brasileira. São Paulo: Quartier Latin, 2006.

DIPP, Gilson Langaro. A cooperação jurídica internacional e o Superior Tribunal de Justiça: comentários à Resolução no 9/05. In: Manual de cooperação jurídica internacional e recuperação de ativos: cooperação em matéria penal. $2^{a}$ ed. Brasília: Ministério da Justiça, 2012, pp. 29-31.

. Carta Rogatória e cooperação internacional. Revista CEJ, Brasília, Ano IX, nº 38, 2007, pp. 39-43.

FRANCESCH, Joan Lluis Perez. Cooperación policial y judicial em la Convención de Prüm. Revista de derecho constitucional europeo, no 7, p. 119-136. Sevilla: Junta Del Andalucia, 2007.

FUX, Luiz. Homologação de sentença estrangeira. In: TIBURCIO, Carmen;

GARCIA, Rafael Arenas. Relaciones entre cooperación de autoridades y reconocimiento. In: Anuário español de derecho internacional privado. Barcelona: Iprolex, 2000, p. 231/260

GILMORE, W.C. Mutual assistance in criminal and business regulatory matters. Cambrigde, Cambridge University Press, 1995.

GODOY, Luiz Roberto Ungaretti de. Crime organizado e seu tratamento jurídico penal. São Paulo: Elsevier, 2011.

LOULA, Maria Rosa Guimarães. Auxílio direto: novo instrumento de cooperação jurídica internacional civil. Belo Horizonte: Fórum, 2010.

MACHADO, Maíra Rocha. Internacionalização do direito penal: a gestão de problemas internacionais por meio do crime e da pena. São Paulo: Ed. 34, 2004.

MADRUGA, Antenor. O Brasil e a jurisprudência do STF na idade média 
da cooperação jurídica internacional. Revista Brasileira de Ciências Criminais, ano 13, nº 54. São Paulo: RT, 2005, p. 291-311.

\section{McCLEAN, J.D. International Co-Operation in Civil and Criminal} Matters. Londres: Oxford University Press, 2002.

MORO, Sérgio Fernando. Cooperação jurídica internacional em casos criminais: considerações gerais. In: BALTAZAR JUNIOR, José Paulo; LIMA Luciano Flores de. Cooperação jurídica internacional em matéria penal. Porto Alegre: Verbo Jurídico, 2010, pp. 14-58.

PAOLUCCI. Chiara Maria. Cooperazione giudiziaria e di polizia in materia penale. Torino: Utet Giuridica, 2011.

PEREIRA NETO, Pedro Barbosa. Cooperação penal internacional nos delitos econômicos. Revista Brasileira de Ciências Criminais, ano 13, n 54. São Paulo: RT, 2005, p. 153-168.

ROCHA, Manuel Antonio Lopes; MARTINS, Teresa Alves. Cooperação judiciária internacional em material penal. Lisboa: aequitas e Editorial Notícias, 1992, p. 14.

SAADI, Ricardo Andrade; BEZERRA, Camila Colares. A autoridade central no exercício da cooperação internacional. In: Manual de cooperação jurídica internacional e recuperação de ativos: cooperação em matéria penal. $2^{a}$ ed. Brasília: Ministério da Justiça, 2012, pp. 21-27.

SANCTIS, Fausto Martins de. Combate à Lavagem de Dinheiro: teoria e prática. Campinas: Millennium, 2008.

SILVA, Marco Antônio Marques da. Acesso à Justiça Penal e Estado

Democrático de Direito. São Paulo: Juarez de Oliveira, 2001.

SILVA, Ricardo Perlingeiro Mendes da Silva. Anotações sobre o anteprojeto de lei de cooperação jurídica internacional. Revista de Processo, ano 35, nº 183. São Paulo: RT, 2005, pp. 133-168. . Cooperação jurídica internacional e auxílio direto. Revista CEJ, Brasília, Ano IX, nº 38, 2007, pp. 39-43.

SOUZA, Carolina Yumi de. Cooperação jurídica em matéria penal: considerações práticas. Revista Brasileira de Ciências Criminais, ano 16, nº 71. São Paulo: RT, 2008, pp. 297-325.

SOUZA, Solange Mendes. Cooperação jurídica penal no Mercosul: 
novas possibilidades. Rio de Janeiro: Renovar, 2011.

STESSENS, Guy. Money Laudering: a new international Law

Enforcment Model. Cambridge: Cambrigde University Press, 2000.

WEBER, Patricia Nuñez. A cooperação jurídica internacional em medidas processuais. Porto Alegre: Verbo Jurídico, 2011.

ZAVASCKI, Teori Albino. Cooperação jurídica internacional e concessão de exequatur. Revista de Processo, ano 35, n 183. São Paulo: RT, 2010, pp. 9-24. In Revista Brasileira de Ciências Criminais, vol. 37. São Paulo: RT, jan./mar. 2002.

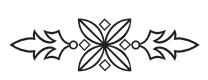

